\title{
A variable-interval timer
}

\section{ARTHUR LEYENBERGER and LAWRENCE M. PAUL Bell Telephone Laboratories, Whippany, New Jersey 07981}

\begin{abstract}
A variable-interval timer with an audible tone output was designed to pace participants in human-factors studies. The timer can be operated in a continuous (recycling) mode or in a time-out ("beat-the-clock") mode. In the continuous mode, the audible tone is emitted at the end of the preset interval and a new timing cycle is begun. In the time-out mode, the research participant must depress a switch both to avoid the tone and to begin a new cycle. The time interval can be digitally programmed for intervals from $1 \mathrm{sec}$ to $2 \mathrm{~h}$ and $45 \mathrm{~min}$. The operation of the timer is described, and construction details are provided.
\end{abstract}

An important part of many human-factors evaluations of apparatus at Bell Laboratories involves having telephone company craftspeople perform in the laboratory tasks for which the equipment was designed. In these studies, craft behavior is observed, allowing the suitability of the apparatus for field use to be estimated. One method used to make the laboratory simulation more realistic and yield the greatest amount of data in a limited time is to increase the participant's rate of responding by pacing.

\section{THE VARIABLE-INTERVAL TIMER}

To accomplish this pacing function by means of an audible tone, we designed and built a variable-interval timer (VIT). The primary function of the VIT is to signal the end of a preset time interval by emitting a $300-\mathrm{msec}$ tone. The range of timing intervals is from 1 to $9,900 \mathrm{sec}(2 \mathrm{~h}$ and $45 \mathrm{~min})$, and the frequency of the tone may be set to $465 \mathrm{~Hz}, 510 \mathrm{~Hz}, 1,030 \mathrm{~Hz}$, $1,230 \mathrm{~Hz}, 1,950 \mathrm{~Hz}$, or $2,690 \mathrm{~Hz}$ (see Figure 1).

\section{VIT Operation}

The VIT requires a separate $5-\mathrm{V}$ power supply. The timing interval is controlled by the two-digit thumbwheel switch and the MULTIPLIER switch. When the MULTIPLIER switch is set at " $\mathrm{X} 1$," the number indicated by the thumbwheel switch expresses the time interval in seconds. At "X10" and "X100," the time interval equals the thumbwheel switch value multiplied by 10 or 100 , respectively.

\section{Continuous Mode}

Once the timing switch is set to RUN, the VIT cycles continuously. At the end of the preset time interval, a tone is emitted and the timer is automatically reset and begins a new timing sequence.

Request for reprints should be sent to L. Arthur Leyenberger, Room 2k-318A, Bell Laboratories, Whippany, New Jersey 07981.

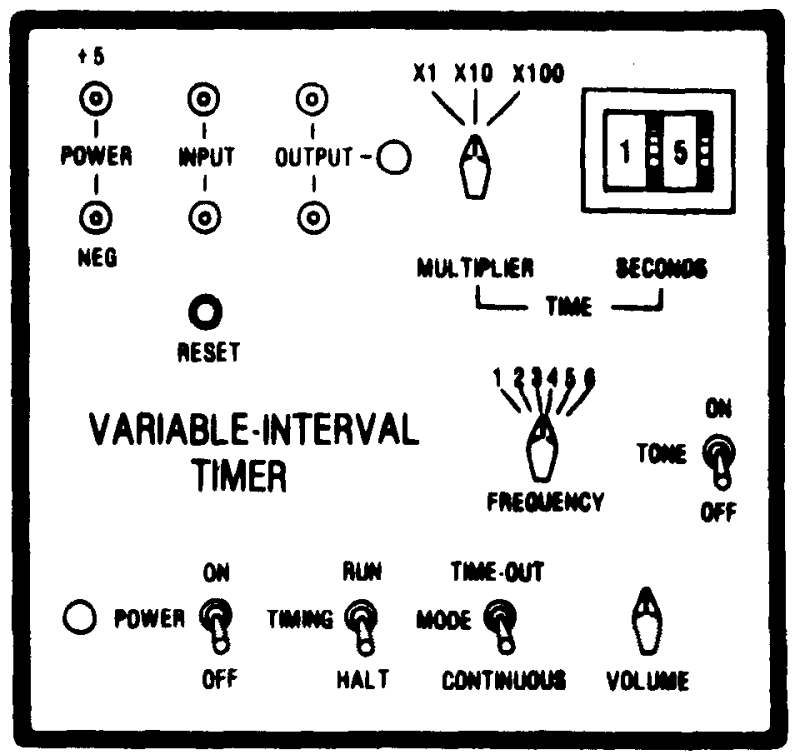

Figure 1. Variable-interval timer.

Time-Out Mode

The time-out mode can be described as a "beat-the clock" arrangement in which an audible tone is emitted after a preset time interval, unless the participant presses a remotely located switch to terminate the time interval, cancel the audible tone, and initiate a new timing cycle.

With the timing switch in the RUN position, the experimenter initiates the time-out cycle by pressing the RESET button, causing the VIT to begin timing until either the interval times out and the audible tone is emitted, or the participant presses a remote switch connected to the two remote-input terminals. If the interval does time out, the VIT enters a standby mode and awaits a push-button response from the participant to begin a new timing cycle.

\section{Circuit Summary}

Figure 2 shows that the output of the thumbwheel switches is converted from two BCD decades to 8-bit binary by the BCD-to-binary converters (Numbers 5 


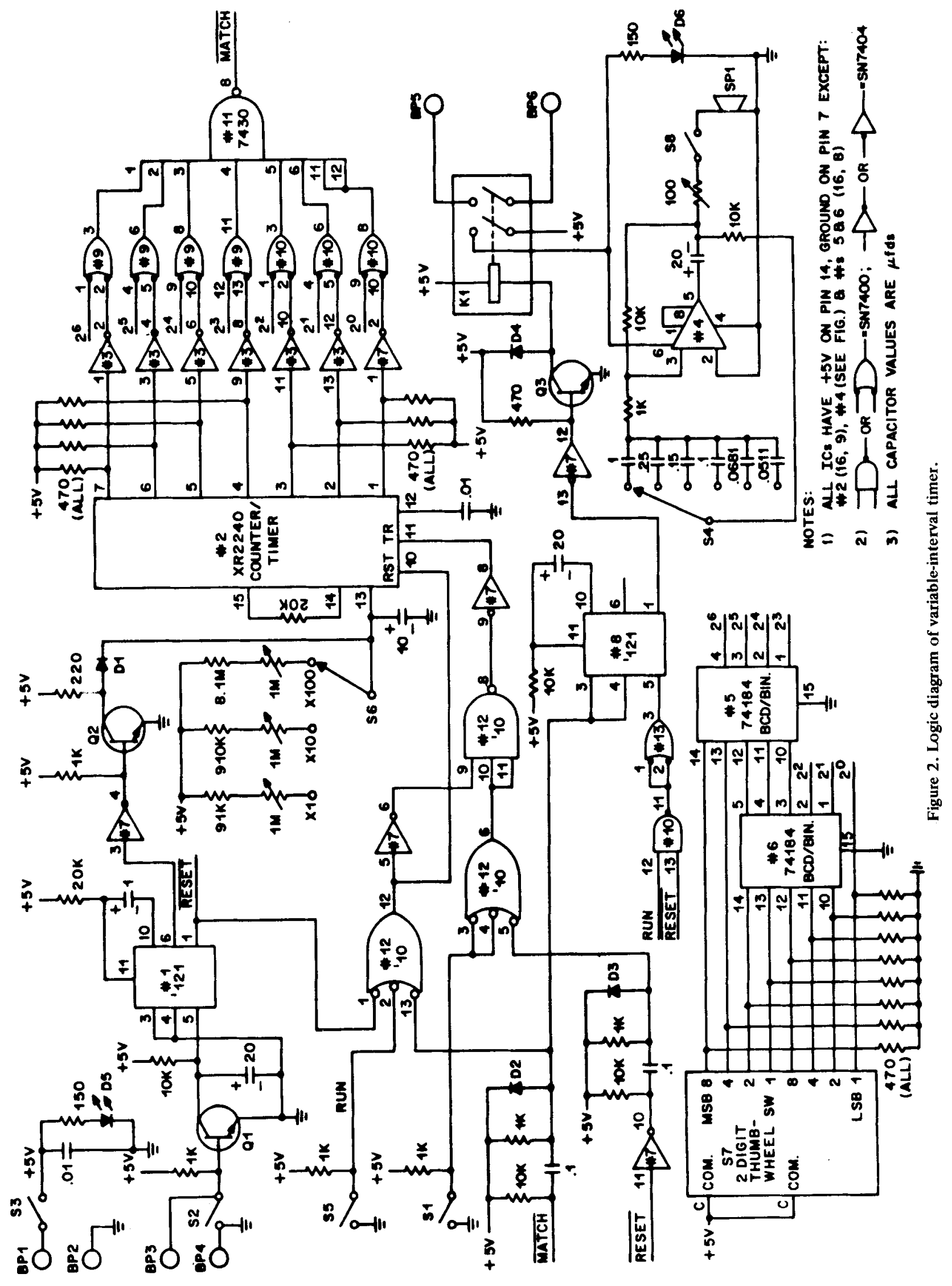


and 6). This binary information is combined with the inverted binary counter outputs of the XR-2240 (Number 2) through two-input NAND gates (Numbers 9 and 10).

The time-base oscillator section of the XR-2240 provides clock pulses to its counter section. Clock pulses are produced every 1,10 , or $100 \mathrm{sec}$ using Switch S6 to select one of three timing resistors. When the binary outputs of the counter section match the binary value from the thumbwheels, the eight-input NAND gate (Number 11) resets the XR-2240 through a three-input NAND gate (Number 12). When the MODE switch (S1) is set to "CONTINUOUS," the XR-2240 is also triggered, and when S1 is set to "TIME-OUT," the XR-2240 is not triggered. In the time-out mode, a contact closure from a remote switch or depression of RESET (Switch S2) is required to trigger the XR-2240. The output of the eight-input NAND gate (Number 11) triggers the one-shot (Number 1) to produce the 300 -msec audible tone.

The $\overline{\mathrm{Q}}$ output of the one-shot operates Relay K1, which operates the tone generator (Number 4) for the duration of the one-shot. The frequency of the tone is determined through one of six capacitors controlled by Switch S4. Switch S8 allows the tone to be turned off, and a potentiometer controls the volume.

In addition to the tone being emitted, an LED (D6) is lit and a contact closure is available across the black binding posts labeled "OUTPUT" (BP 5 and BP 6) for operating other apparatus.

\section{SUMMARY}

The VIT provides a relatively inexpensive and accurate means for pacing subjects in human-factors experiments. This pacing may be done directly by the VIT's audible tone or by other output devices controlled through the VIT's output port. The timing accuracy of the VIT is within $1 \%$ of the value set by the thumbwheel switches and MULTIPLIER switch over all the timing ranges once the trimmer potentiometers are optimally adjusted. Table 1 identifies the component parts.

Table 1

List of Component Parts

\begin{tabular}{|c|c|c|c|}
\hline Part Number & Quantity & Type & Description \\
\hline BP1, BP3, BP4 & 3 & Red & Binding post \\
\hline $\mathrm{BP} 2, \mathrm{BP} 5, \mathrm{BP} 6$ & 3 & Black & Binding post \\
\hline D1-D4 & 4 & $1 \mathrm{~N} 914$ & Switching diode \\
\hline D5 & 1 & Red & LED \\
\hline D6 & 1 & Orange & LED \\
\hline $\mathrm{K} 1$ & 1 & DPST & 3-V reed relay (e.g., Wabash No. 822-202) \\
\hline S1, S3, S5, S8 & 4 & SPST & Toggle switch (MODE, POWER, TIMING, TONE) \\
\hline$\$ 2$ & 1 & SPST & Momentary contact switch (RESET) \\
\hline S4 & 1 & 6 position & Rotary switch (FREQUENCY) \\
\hline S6 & 1 & 3 position & Rotary switch (MULTIPLIER) \\
\hline S7 & 1 & 2 digit & BCD thumbwheel switch (TIME) \\
\hline SP1 & 1 & $8 \mathrm{ohm}$ & Speaker \\
\hline Q1-Q3 & 3 & NPN & Switching transistor (e.g., Radio Shack No. 276-2010) \\
\hline$\# 1, \# 8$ & 2 & SN74121 & Integ. Ckt. monostable multivibrator \\
\hline$\# 2$ & 1 & XR-2240 & Integ. Ckt. EXAR prog. counter/timer \\
\hline$\# 3, \# 7$ & 2 & SN7404 & Integ. Ckt. hex inverter \\
\hline$\# 4$ & 1 & LM386 & Integ. Ckt. low-voltage audio amplifier \\
\hline$\# 5, \# 6$ & 2 & SN74184 & Integ. Ckt. BCD to binary decoder \\
\hline$\# 9, \# 10, \# 13$ & 3 & SN7400 & Integ. Ckt. quad 2-input NAND gate \\
\hline \#11 & 1 & SN7430 & Integ. Ckt. 8-input NAND gate \\
\hline \multirow[t]{17}{*}{$\# 12$} & 1 & SN7410 & Integ. Ckt. triple 3-input NAND gate \\
\hline & 1 & & Enclosure (e.g., Global Specialties No. DMC-1) \\
\hline & 2 & $150 \mathrm{ohm}$ & Resistor \\
\hline & 1 & $220 \mathrm{ohm}$ & Resistor \\
\hline & 16 & $470 \mathrm{ohm}$ & Resistor \\
\hline & 7 & $1 \mathrm{kohm}$ & Resistor \\
\hline & 6 & $10 \mathrm{kohm}$ & Resistor \\
\hline & 2 & $20 \mathrm{kohm}$ & Resistor \\
\hline & 1 & $91 \mathrm{kohm}$ & Resistor \\
\hline & 1 & $910 \mathrm{kohm}$ & Resistor \\
\hline & 1 & 8.1 megohm & Resistor \\
\hline & 3 & 1 megohm & Trimmer potentiometer \\
\hline & 1 & $100 \mathrm{ohm}$ & Potentiometer \\
\hline & 2 & .01 microfarad & Capacitor \\
\hline & 1 & .0511 microfarad & Capacitor \\
\hline & 1 & .0681 microfarad & Capacitor \\
\hline & 3 & .1 microfarad & Capacitor \\
\hline
\end{tabular}


LEYENBERGER AND PAUL

Table 1 Continued

\begin{tabular}{cccc}
\hline Part Number & Quantity & Type & Description \\
\hline 1 & .15 microfarad & Capacitor & \\
1 & .25 microfarad & Capacitor & \\
2 & 1 microfarad & Capacitor & \\
1 & 10 microfarad & Capacitor & Capacitor \\
3 & 20 microfarad & Cara
\end{tabular}

Note-All integrated circuits are available from Jameco Electronics, 1355 Shoreway Rd., Belmont, California 94002.

(Received for publication September 17, 1982; accepted October 10, 1982.) 